19 Revue d'histoire du XIXe siècle

Société d'histoire de la révolution de 1848 et des

révolutions du XIXe siècle

37 | 2008

L'ère victorienne revisitée

\title{
Malcolm CHASE, Chartism: A New History
}

Fabrice Bensimon

URL : http://journals.openedition.org/rh19/3550

DOI : 10.4000/rh19.3550

ISSN : $1777-5329$

Éditeur

La Société de 1848

Édition imprimée

Date de publication : 15 novembre 2008

Pagination : 185-242

ISSN : 1265-1354

Référence électronique

Fabrice Bensimon, "Malcolm CHASE, Chartism: A New History », Revue d'histoire du XIXe siècle [En ligne], 37 | 2008, mis en ligne le 01 décembre 2008, consulté le 22 septembre 2020. URL : http:// journals.openedition.org/rh19/3550; DOI : https://doi.org/10.4000/rh19.3550

Ce document a été généré automatiquement le 22 septembre 2020.

Tous droits réservés 


\title{
Malcolm CHASE, Chartism: A New History
}

\author{
Fabrice Bensimon
}

\section{RÉFÉRENCE}

Malcolm CHASE, Chartism: A New History, Manchester, Manchester University Press, 2007, 431 p. ISBN : 978-0-7190-6087-8 (broché) et 6086-1 (relié). 18,99 livres sterling (broché) et 60 livres sterling (relié).

1 Entre 1838 et 1848, en Grande-Bretagne, des millions d'hommes et de femmes - trois millions au plus fort du mouvement -, essentiellement issus des classes populaires, ont lutté pour la "Charte du peuple», un programme politique articulé autour de six points (le suffrage universel, l'abolition du cens d'éligibilité, la rémunération des députés, l'égalité des circonscriptions, le secret du scrutin et l'élection annuelle du Parlement). Et, jusqu'en 1858, des minorités ont entretenu cette tradition. Le chartisme fait aujourd'hui partie de la mémoire collective britannique ${ }^{1}$. Et il a donné lieu aux débats historiographiques les plus importants, comme celui sur le linguistic turn dans les années $1980^{2}$. On pouvait craindre que, en tant qu'objet historique, il pâtisse aujourd'hui du déclin de l'histoire ouvrière. Le livre de Malcolm Chase constitue un brillant retour en grâce de cet épisode fondateur, peu connu en France. Et même outreManche, où, depuis un demi-siècle, de nombreuses monographies ont porté sur tel ou tel épisode, on ne comptait pas à proprement parler d'histoire du chartisme.

Chartism: A New History suit un plan chronologique, et revient donc sur les épisodes et les modalités d'un mouvement qui s'inscrit tout à la fois dans les luttes radicales menées depuis la fin du XVIII e siècle contre la "Old Corruption », avec la pétition comme moyen d'action privilégié, et revêt en même temps plusieurs traits nouveaux sur le plan de l'organisation ouvrière : la mass platform, un journal populaire durable à grand tirage (le Northern Star), des orateurs itinérants s'adressant à des meetings de masse tenus en plein air, une direction nationale reconnue et des débats, voire des tentatives 
pratiques de renversement du pouvoir par la force. L'ouvrage de Malcolm Chase est un "narrative ", un véritable récit qui tient le lecteur en haleine. Il repose sur la maitrise de vastes sources, dont l'intégralité des journaux chartistes, les mémoires rédigées par d'anciens militants, les rapports de police, et quelques inédits. S'appuyant sur l'abondante presse locale de l'époque, Malcolm Chase restitue le chartisme dans la diversité des métiers et des régions - il a recensé quelque 640 communautés locales différentes.

3 Le livre est traversé par la popularité flamboyante de Feargus O'Connor, le principal dirigeant chartiste, orateur charismatique et infatigable, vilipendé par les élites, et qui contribua, malgré ses limites, à donner aux classes populaires de l'époque une certaine confiance dans leurs capacités à intervenir dans un champ politique à l'écart duquel voulaient les tenir l'aristocratie et la bourgeoisie. Malcom Chase a exhumé l'étonnante correspondance du directeur du Northern Star avec son frère, révélant son admiration pour le premier ministre tory Robert Peel. Mais, loin de se focaliser sur les dirigeants, ce livre fait également revivre plusieurs personnalités de second plan, voire des anonymes du chartisme. Chaque chapitre est en effet suivi d'une petite biographie de personnalités en général peu connues. Ces portraits illustrent la diversité des engagements des chartistes: issus des classes moyennes mais surtout du monde ouvrier; hommes, femmes, enfants même, tels Ann Dawson, sept ans, l'auteure d'une superbe broderie. Ils témoignent aussi des risques encourus par les militants, à l'instar de Samuel Holberry, mort à vingt-sept ans d'une tuberculose contractée dans une prison où il doit, pour payer ses repas, tourner une manivelle huit heures par jour; ou de William Cuffay, né aux Antilles anglaises, fils d'un esclave africain, devenu tailleur londonien et dont l'activité sans compromis lui valut en 1848 d'être déporté en Tasmanie, où il mourut dans la pauvreté. En même temps, Malcom Chase montre que les autorités surent graduer la répression, et veillèrent à ne pas faire de martyr : on emprisonne (jusqu'à 500 militants en 1840), on déporte, mais contrairement à ce qui se faisait vingt ans auparavant, on n'exécute plus, même s'il s'en fallut parfois de peu.

4 Si l'ouvrage est un récit, et non une discussion historiographique, il n'esquive pas les débats en cours. Par exemple, sur la question de la participation des femmes, l'historienne Anna Clark avait souligné que les hommes chartistes donnaient aux femmes un rôle secondaire, contrôlaient étroitement leurs réunions et adoptaient la rhétorique patriarcale de la domesticité et des sphères séparées ${ }^{3}$. Malcolm Chase montre que, dans la première phase du chartisme, la participation des femmes était élevée, avec une centaine d'associations de femmes chartistes formées en 1838-39. En outre, on faisait signer les femmes (qui représentent 15 à 20 pour cent des pétitionnaires de 1839), ce qui était novateur dans un monde du travail de plus en plus sexué. Puis, dans un second temps, le chartisme cesse de mobiliser des communautés entières pour s'inscrire dans l'idéal victorien dominant du chef de famille (male breadwinner) et chercher ainsi à gagner en respectabilité ; les associations féministes périclitent et, en 1848 , les femmes ne représentent plus que huit pour cent des signataires.

5 La culture chartiste occupe ici une place de choix. La presse chartiste était diverse, et le Northern Star fut un des plus gros tirages de l'époque. Les journaux étaient prêtés et souvent lus publiquement à haute voix, et leur typographie aidait à transformer ces lectures en des événements quasi théâtraux. Le chartisme fut à la charnière entre une culture populaire orale et celle de l'imprimé. La poésie y avait une place privilégiée, 
ainsi que les romans. Les églises et les écoles chartistes sont évoquées, ainsi que le rôle du pub, la nature du meeting de plein air, les débats sur la tempérance et l'abstinence d'alcool, le chant choral et les codes vestimentaires. S'appuyant sur deux sujets dont il est aussi spécialiste, Malcom Chase s'attarde également, d'une part, sur l'importance jouée par les trade-unions dans le développement du chartisme et, d'autre part, sur le projet chartiste de "plan agraire» (Land Plan) de retour à la terre, qui aboutit à la formation de petites communautés chartistes agricoles à partir de $1845^{4}$.

Il reste à espérer que cet ouvrage sera traduit en français, où la seule et dernière histoire du chartisme remonte à... $1913^{5}$. Il s'agit non seulement, on l'aura compris, d'une somme érudite, mais aussi d'un livre captivant et émouvant, sur un des moments clés de l'histoire du mouvement ouvrier.

\section{NOTES}

1. On notera, par exemple, le succès du site animé par Mark Crail, Chartist Ancestors' Website, dont l'accroche est immanquable : "What did your ancestors do during the revolution? ", ainsi que le «Chartism Day » organisé chaque année par Joan Allen et Owen Ashton.

2. . Voir notamment le texte de Gareth Stedman Jones, « Rethinking Chartism », dont une partie a récemment été publiée en français: "Repenser le chartisme», Revue d'histoire moderne et contemporaine, 54-1, 2007, p. 7-68, traduction française par Daniel Argelès et Philippe Minard.

3. . Anna Clark, The Struggle for the Breeches: Gender and the Making of the British Working Class, Berkeley, University of California Press, 1995.

4. . Voir Malcolm Chase, “The People's Farm”. English Radical Agrarianism 1775-1840, Oxford, Oxford University Press, 1988 ; Malcolm Chase, Early Trade Unionism: Fraternity, Skill and the Politics of Labour, Aldershot, Ashgate, 2000.

5. . Édouard Dolléans, Le chartisme (1831-1848). Aurore du mouvement ouvrier, Paris, Les Nuits Rouges, 2003 ( $1^{\text {re }}$ édition 1912-1913). 